\title{
LOS INICIOS DE LA REFLEXIÓN SOBRE MÚSICA Y SOCIEDAD EN LA GRECIA ANTIGUA
}

\author{
María Luz Rivera Fernández \\ Profesora de conservatorio Comunidad de Madrid \\ mlrivera@educa.madrid.org
}

\section{RESUMEN}

El presente artículo se propone presentar un panorama de algunos testimonios literarios y filosóficos griegos acerca de los comienzos de la reflexión sociológica sobre la importancia de la música para la configuración armónica de la sociedad y para el mejoramiento personal del individuo en su seno. Según nuestra interpretación, estas dos nociones, que han sido posteriormente recuperadas en la historia del pensamiento utópico y en la sociología -que, desde finales del siglo XIX, ha usado el hecho musical como modelo social- encuentran sus raíces en la tradición de la educación griega, en las ideas del antiguo pitagorismo y en las interpretaciones sobre música y sociedad que incluyeron Platón y Aristóteles en sus obras políticas. Si nuestra hipótesis se confirma, y este artículo es parte de una investigación doctoral sobre la recepción de estas dos nociones en la historia de las ideas y de la sociología, la moderna sociología de la música (Musiksoziologie) dependería directamente de la paideia musical griega y de las ideas utópicas sobre la sociedad ideal a través de la música que provienen de la Grecia antigua.

Palabras clave: Música y Sociedad en la Grecia antigua, Educación en la Grecia antigua, Pitagorismo, Platón, Aristóteles.

\section{ABSTRACT}

This article aims to present an overview of some Greek literary and philosophical statements about the beginnings of the sociological reflection on the importance of music for the shaping of an harmonious society and for the self-improvement of the individual 
within it. According to our interpretation, the origin of these two notions, which have been subsequently recovered both in the history of Utopian thought and in sociology -which has used music as a model social since the late 19th Century- can be traced in the tradition of Greek Education, in ancient Pythagoreanism and in the interpretations of music and society offered by Plato and Aristotle in his political works. If our hypothesis is confirmed, and this article is a piece of a $\mathrm{PhD}$ research on the reception of these two notions in the history of ideas and of sociology, the modern sociology of music ( $\mathrm{Mu}$ siksoziologie) would depend directly from the Greek musical paideia and from these utopian ideas about an ideal society through music stamming from Ancient Greece.

Key words: Music and Society in Ancient Greece, Education in Ancient Greece, Pythagoreanism, Plato, Aristotle.

Al hablar de la música en la sociedad griega, debemos situarnos en la íntima relación de las artes o ciencias (technai) entre sí en esta época histórica. Los griegos de la época arcaica, empezaron ejerciendo dos tipos de artes: uno era expresivo y otro constructivo. El primero, como un todo, lo formaba la poesía, la música y la danza. El segundo la arquitectura, la escultura y la pintura. «El arte expresivo se basaba en la danza, acompañada de palabras y sonidos musicales, formando un solo arte, la «triunica choreia», como la llamó Tadeusz Zielinski» ${ }^{1}$. Este arte consistía en la expresión de los sentimientos mediante sonidos y movimiento, mediante palabras, melodía y ritmo. El término «música» o «arte musical» (mousiké techne) merece una consideración aparte y muy especial. Es, por supuesto, el arte de las Musas, las nueve divinas doncellas del séquito de Apolo, que incluía la poesía, la danza y la gimnasia, pero también «especulación cósmica y otras ramas de la educación con el arte del sonido» ${ }^{2}$. Ya el pensador Sexto Empírico ${ }^{3}$ advierte de que la palabra «música» se usa de tres formas distintas: como ciencia que trata la melodía y la creación de ritmos, como práctica instrumental de los músicos propiamente dichos en su ejecución de piezas y, por último, «como la corrección de algo determinado, como cuando decimos que una obra es armoniosa y hablamos de quien ha conseguido tal corrección como de alguien inspirado por las Musas» ${ }^{4}$.

Conformaba, pues, la música en la antigüedad una educación integral y no solo musical que resultaba básica en la formación del individuo y en su integración en la sociedad. Así afirmaba Ateneo que «la antigua sabiduría se concedía sobre todo a la música ${ }^{5}$ y Aristides Quintiliano sostiene que la música es el arte más perfecto, pues mientras que la pintura o la escultura persiguen al belleza visual en una pequeña porción o durante un momento, la música es positiva en todo tiempo, ya que ordena el alma y su tarea es «reunir y armonizar todo cuanto tiene la naturaleza ${ }^{6}$. La mousiké es entendida como conjunción de poesía, música y danza y se la considera la más eficaz vía para la educación del individuo en diversos textos clave de la cultura antigua a los que se pasará

\footnotetext{
1 Apud Tatarkiewicz, 1987, 22.

2 Rowell, 1990, 47.

3 Sexto Empírico, Adv. Math. VI 1-2.

4 Martínez Hernández 2010, 12.

5 Ateneo, Deipn. 14, 632e.

${ }^{6}$ Arístides Quintiliano, Sobre la música I 10-20.
} 
revista a continuación, como muestra de que el poder socialmente transformador de la música se encuentra inserto en los orígenes mismos de nuestra civilización.

Debemos aproximarnos así a un concepto mucho más amplio de la música, no sólo por su extensión sino por el numero de actividades que incluía, ya que no se daba la distinción o la acotación de los campos o actividades artísticas tal y como las entendemos hoy en día. La asociación directa de la música con la danza se da en todas las culturas antiguas y no es posible delimitar un campo de la música exclusivamente instrumental ya que música y danza aparecen unidas en la expresión de un mismo tipo de celebraciones de tipo lúdico, fiestas, conmemoraciones, o actos de tipo ritual, religiosos o civiles.

«Una educación de cuño aristocrático, exigía, pues, el aprendizaje de la lira, el canto y la poesía, así como de la danza y la gimnasia» ${ }^{7}$. «La música era considerada como algo valioso y desconfiable a la vez: valioso por su capacidad de despertar, complacer y regular el alma y de producir buenas cualidades en sus oyentes, pero se desconfiaba de ella por su capacidad de sobreestimular, drogar, distraer y llevar a excesos a la conducta ${ }^{8}$.

El papel que más tarde corresponderá al teatro y a la música, lo desempeña en origen la danza. Se practicaba dentro de las funciones rituales de los misterios y de los ritos dionisíacos. «Servía para apaciguar y aliviar los sentimientos, o empleando el lenguaje de aquel entonces, para purificar las almas» ${ }^{9}$. Las expresivas danzas de culto no son una particularidad de la cultura griega sino que están presentes en casi todas las culturas del mundo. En la cultura griega las practicaban aún cuando habían conseguido el cénit de su cultura; la danza ejercía una gran influencia sobre el pueblo griego y no sólo la ceremonia de los sacerdotes sino un espectáculo para las masas. Con el tiempo, se produce un desarrollo separado de la música, la danza y la poesía como artes independientes. La música siguió teniendo su vinculación con el culto. De hecho, de los diversos cultos a los dioses surgieron distintos géneros musicales-poéticos: el peán era cantado en honor a Apolo, el ditirambo se cantaba para Dioniso en las fiestas de primavera y la prosodia en ciertas procesiones, aparte de una infinidad de danzas y tonadas, militares o civiles, corales o monódicas.

La relación de la música con la religión se mantuvo y fue introducida en fiestas profanas, públicas y paganas. Las sectas órficas creían que la música que producían arrancaba al alma de sus lazos corporales. Pero se debe sin duda a la escuela pitagórica, fundada en el Sur de Italia por el filósofo y chamán Pitágoras de Samos en el siglo VI a. C. De los pitagóricos se decía que avanzaron sobremanera en la matemática y en la música y se atribuía su invención directa a Pitágoras, así como la configuración de una filosofía completa del orden universal basada en principios numéricos: un ordenamiento de los astros, los planetas divinos y toda la realidad de uno y otro plano con el trasfondo del número, que armoniza el cosmos con una música matemática celestial que regula sus movimientos y relaciones. Los intervalos entre los cuerpos celestes estarían, así, determinados por las leyes de la armonía musical, de donde surge la célebre doctrina atribuida a Pitágoras de la armonía de las esferas ${ }^{10}$. Una música producida los cuerpos celestes con

\footnotetext{
${ }^{7}$ Fubini, 1988, 31.

${ }^{8}$ Rowell, 1990, 47

9 Rowell, 1990, 23.

${ }^{10}$ P.e., Plinio, Nat. Hist. II 20. Cf. en general Hernández de la Fuente 2011.
} 
su movimiento que, sin embargo, sobrepasaba la capacidad del oído humano y solo era audible para las almas sin cuerpo y quizá para el propio Pitágoras ${ }^{11}$.

Como resultado de todo lo anterior, de la configuración matemática del universo, de los cuerpos celestes y de su proporción, se decía también que para los pitagóricos el movimiento circular de las estrellas producía una cierta armonía, una música celestial que excedía las capacidades humanas. Para explicar por qué no podemos oírla, Aristóteles recurría a la siguiente imagen: «a los hombres les pasa como a los herreros, que están tan acostumbrados a este ruido que no se dan cuenta de él» ${ }^{12}$. Acaso Pitágoras concibiera un sistema matemático-musical y descubriera la relación aritmética existente en la escala musical mediante la observación accidental de los sonidos producidos sobre unas cuerdas por pesos diferentes, como quiere la tradición ${ }^{13}$. Resulta especialmente relevante la idea pitagórica de la música como medicina del alma y elemento que ayuda a regular las pasiones, especialmente la ira: la virtud más elevada era una especie de armonía o acorde musical del alma que permite el autocontrol ${ }^{14}$. Un aspecto interesante del régimen de vida pitagórico era, así, el uso constante de música, danza y meditación, pues consideraban la poesía y la melodía medicinas del espíritu ${ }^{15}$. Por ello, dice el geógrafo Estrabón, «Platón, e incluso antes de él los pitagóricos, llamaban a la filosofía música» ${ }^{16}$.

La escuela de Pitágoras en la Magna Grecia, concibió una teoría musical que giraba en torno a la ordenación de las series numéricas y cuyo elemento nuclear es la armonía plasmada en los intervalos que condicionan cualquier relación matemática o composición musical. En este último caso, la consecución de la armonía oscila entre la tonalidad y la atonalidad y, como consecuencia de esta visión teórica, se extrae un rechazo de la disarmonía. Esto tiene repercusiones para la educación ética y política que propugnaba la escuela pitagórica, procurando un orden (kosmos) correcto de la vida pública y del alma.

La idea de la armonía, la amistad y la proporción propugnada por los pitagóricos tenía una clara vertiente ética, pero también política ${ }^{17}$. La proporción matemático-musical entre las clases sociales conformaba para la política pitagórica un equilibrio áureo, un logismós («cálculo» o «razonamiento»). Así, las nociones de armonía de las esferas y del universo tenían también un reflejo, en el marco del método comparativo entre individuo y sociedad, en la vida cotidiana y en la política. La armonía política, aparentemente defendida por los antiguos pitagóricos, fue una especie de leitmotiv que más tarde reutilizarían Platón y Aristóteles.

Debemos al Pseudo-Plutarco las primeras teorías sobre el origen de la música, en su obra De Musica. Este autor hace retroceder hasta Homero doctrinas posteriores al poeta, teorías ético educativas de carácter musical. «La música se introdujo por considerársela capaz de combatir y calmar el efecto excitante producido por el vino...entonces, la música, por el efecto del orden y la mesura que le son propios llevaría de nuevo a los hombres

11 Platón, Resp. 616-7. Aristóteles, De Caelo II 9.

12 Aristóteles, de caelo B 9, 290 b 12.

13 Dióg. Laercio, ibid.

14 Porfirio, Vit. Pyth. 30, Dióg. Laercio VIII, 33.

15 Porf, Vit. Pyth. 32-33, 40. Sobre la meditación, Riedweg 2002 [2005] 32.

16 Estrabón X 39 - 10

17 Kahn 2001, 47, Konstan 1997, 115. 
al camino recto y los volvería cuerdos» ${ }^{18}$. La convicción de la bondad de los efectos pacificadores de la música llevó a los legisladores griegos a introducirla dentro del sistema educativo. Esta tradición pedagógica pervivió en sistemas educativos posteriores de la Edad Media y llega hasta nuestros días.

La gran poesía épica de los griegos, bajo el signo de la musa Calíope, nació en los siglos VIII y VII: La Ilíada en el VIII y la Odisea en el VII. Fue la primera poesía escrita en Europa y de una perfección insuperable. Se basaba en la tradición oral, existen varias teorías acerca de sus autores. Lo cierto es que esta poesía fue rodeada por un aura de leyenda. «El nombre de Homero significaba lo mismo que poeta. Lo veneraban como a un semidios y consideraban su obra poética como libro sagrado» ${ }^{19}$. La poesía homérica contribuyó a la formación de la religión olímpica, que estaba llena de mitos. Sus héroes eran tanto hombres como dioses. Pero en este mundo reinaba el orden. Todo sucedía de manera racional, el comportamiento de los dioses estaba regido por la naturaleza más que por fuerzas sobrenaturales.

Al estar vinculada con los ritos, la poesía griega es de carácter público, social, colectivo y estatal. Era considerada un elemento indispensable en las ceremonias públicas y se preocupaban por su nivel artístico. «La épica de Homero, tras ser introducida en los programas oficiales de las fiestas estatales en Esparta, Atenas y otras ciudades, se convirtió en patrimonio común de todos los griegos» $»^{20}$.

La poesía no era de lectura personal, como la entendemos en la actualidad de forma más confidencial, íntima o personal, sino que estaba destinada a ser hablada y cantada. «La poesía, tanto la colectiva como la ritual, era una expresión de sentimientos y fuerzas sociales más que de sentimientos personales. Era utilizada como arma en la lucha social: algunos poetas pusieron sus obras al servicio de la nueva democracia, mientras que otros pretendían defender el pasado» ${ }^{21}$. La primitiva música de los griegos estaba en estrecha relación con la poesía lírica, que surge a lo largo de los siglos VII y VI. Se trata de $t a$ lyriká, la poesía lírica o, literalmente, «las [piezas] para ser entonadas al son de la lira», que representa, tras la épica heroica de Homero y la didáctica de Hesíodo, el surgimiento de la subjetividad del poeta. Antes el yo del poeta se sume en la colectividad: a partir de Alceo, Alcmán, Safo o Anacreonte se produce el nacimiento y la expresión de la emotividad personal del poeta, de sus sentimientos y opiniones, violentas, dulces o encontradas. La lírica coral, de raíz doria, para ser entonada al son de la música con la danza acompasada de un coro de jóvenes o doncellas o la lírica monódica, es decir, la monodia o «canto de uno solo», son las dos clases principales. No había más música que la vocal y la poesía siempre estaba acompañada de la música. Los instrumentos servían como acompañamiento -lira, aulós, percusión...- y no se puede hablar de una música instrumental. La fusión de poesía y música era una constante y no se podía pensar en una sin la otra. Las formas de la poesía eran las de la música, como el ditirambo, que según Aristóteles dará lugar con el tiempo al surgimiento del tercer género poético-musical tras la épica y la lírica: la poesía dramática. Los esquemas rítmicos de la poesía se convirtieron en los modelos de

\footnotetext{
${ }_{18}$ Pseudo Plutarco, De la Musica, Graf Verlag 1954, 15-25 cap. 15-25

19 Tatarkiewitz, 1987, 26.

20 Tatarkiewitz, 1987, 27

21 Tatarkiewitz ibid.
} 
los esquemas rítmicos de la música. Sabemos que la música que acompañaba la poesía griega de la era arcaica estaba basada en unos patrones fijos que se iban improvisando, adaptándose a los acentos de las palabras y a la sintaxis ${ }^{22}$. Formalmente y en su contenido y en su expresión, la música estaba en perfecta unión con la poesía y con el texto que le daba su razón de ser, pertenecían a la misma expresión de un solo contenido común de raíz semántica. Quizás podemos ver esta íntima unión de la música y la poesía en una de las formas más románticas por excelencia que es el Lied, o canción alemana, que tiene su culminación en el romanticismo y trata de llevar a su culminación la unión y la expresión del texto a través de la música. El Lied se convertirá en un género musical específico que crea una tradición de expresión a través de la palabra poética, acaso como última repercusión de la lírica griega y recreación fiel y a la par distante. También en los géneros de música más tradicional y popular, los cantautores intentarán dar más supremacía a los textos o letras de sus canciones, y entronca con la tradición más literaria y romántica.

El papel de la música en la antigua Grecia será indispensable en la construcción de la buena sociedad: la ética y la estética quedan, en el caso de la música, indisolublemente unidas. Para E. Fubini no hay duda de que la música desde tiempos arcaicos en Grecia, formaba parte del sistema educativo de los niños y jóvenes, hacia el siglo VII y VI, primero en Esparta y después en Atenas, debido a la labor desarrollada por los líricos más arcaicos $^{23}$. El mítico Terpandro en el siglo VII habría instaurado la enseñanza de la música en Esparta: se dice que perfeccionó la lira, aumentando su número de cuerdas que pasa de 4 a 7, queriendo demostrar su superioridad sobre la flauta o aulós (instrumentos rivales en Grecia). La tradición recogida por el Pseudo-Plutarco le atribuye la invención de los nomoi: Melodías que se establecen de forma rígida para distintas ocasiones en función del efecto que se intenta producir en el auditorio y que se convierten en la base de la tradición musical posterior.

«El nomos de Terpandro era una melodía monódica compuesta de siete partes. En cuatro ocasiones triunfó en Delfos antes de que se convirtiera en forma obligatoria, constituyendo un esquema sobre el cual se adaptaban varios textos» ${ }^{24}$. Estos nomoi, según el testimonio de Platón en las Leyes «debieron representar la tradición musical más antigua y austera: la música concebida conforme a una rígida ley, música sin corromper por los nuevos usos y costumbres» ${ }^{25}$. Platón en las Leyes, relaciona la decadencia de la tradición musical de su época (la época clásica) con la confusión reinante en los géneros musicales y la desaparición de los nomoi. Como expresa en el Libro III: en el dominio de la música nació la opinión de que todo el mundo entendía de todo y podía juzgar acerca de los nomoi, con lo que vino el relajamiento...»como consecuencia de esa libertad viene el negarse a obedecer a las autoridades, luego se huye de las servidumbre y no se hace caso de las advertencias del padre, de la madre y de las personas de edad, de las leyes, de las promesas adquiridas y hasta de los mismos dioses» ${ }^{26}$. En fin, Platón ve el abandono de los nomoi musicales como el principio para llegar a la falta de respeto a todo tipo de ley

${ }^{22}$ Bergua, 2012, 29. En este ensayo Bergua estudia de forma minuciosa la relación textual-musical desde la Antigüedad, así como los distintos métodos de notación musical.

${ }^{23}$ Fubini, 1990, 35.

24 Tatarkiewitz, 1987, 26.

25 Fubini, 1990, 36.

${ }_{26}$ Platón, Las Leyes, Libro III, 700-1 
y autoridad existente. Recordemos que la mencionada obra de Platón se titula en griego precisamente Nomoi, que quiere decir a la par «leyes» y «modos musicales». La palabra se relaciona etimológicamente con el verbo griego nemo, «distribuir o repartir», y el sustantivo nomos implica una porción, la parte equitativa y proporcionada, con un sentido de armonía entre las partes y el todo que se aplica en griego antiguo tanto al ámbito jurídico como al de la música.

Se deduce de las fuentes literarias al respecto que «la música que acompañaba a la poesía en la era arcaica debía ser a menudo, si no casi siempre, de cuño tradicional, semi-improvisada sobre patrones prefijados como sabemos que ocurría en el caso de la épica, cantada sobre un esquema melódico básico que podía adaptarse a los acentos de las palabras y la sintaxis» ${ }^{27}$. Para ser un buen compositor había que conocer el sistema teórico para seleccionar el material adecuado y ajustarlo al texto con precisión, conocer bien los efectos producidos por los distintos nomoi. «Se reconocía a la proporción abstracta (expresada en relaciones numéricas simples) como el principio formal supremo, la escala teórica sobre la cual se debía desplegar la obra de arte... La imitación era la técnica básica y el criterio por el cual se debía juzgar una obra» ${ }^{28}$. La mímesis de los paradigmas apropiados o de la naturaleza marcará el debate sobre el arte, desde la poesía a la música, a lo largo de toda la antigüedad y después en su recepción renacentista. Ejemplos de ello son el dilema estético y filosófico que planteará Platón en la República (¿cuáles son los modelos artísticos dignos de emulación para una correcta educación del ciudadano) y la consideración aristotélica del ars imitatur natura, retomada por otros pensadores y poetas $^{29}$.

La música está presente en todas las obras de Platón. No hay ningún diálogo platónico en el que no se trate el tema de la música. Analizaremos la relevancia fundamental de la música para la educación en todo el proyecto filosófico, y también político, de Platón. Una educación que tiene en cuenta la división social por estamentos en virtud de las capacidades, como aparece en la República. Cada cual será educado según su pertenencia y su función y el proyecto solo dedica atención a la educación de las dos clases superiores, y sobre todo de la dirigente. La educación propuesta oscila entre tradición e innovación, pues contiene rasgos típicos de la paideia griega, como la mezcla entre la educación física y la literaria o musical, pero a la vez censura en esta última disciplina a los poetas tradicionales de la mitología del politeísmo griego -notablemente Homero y Hesíodo, pero también a los trágicos, tan relacionados con la democracia ateniense- y propone nuevos paradigmas para la educación de las clases dirigentes. Además del énfasis en la música, la geometría, la aritmética o la astronomía, la educación platónica de la república deja un resquicio para otro tipo de poesía musical y coral, también parte del conglomerado de la tradición, pero relacionado con otro tipo de religión.

De entre todos los diálogos de Platón, resaltan por su importancia en el tratamiento del tema La República, Las Leyes, Timeo, Fedón y Fedro. De estos diálogos resultan las distintas y a veces contradictorias opiniones sobre la música. «Platón parece oscilar entre una condena radical de la música y una consideración de la misma como suprema forma

\footnotetext{
27 Bergua, 2012, 29.

28 Rowell, 1990, 49.

29 Büttner, 2006, 62 ss.
} 
de belleza, y por tanto, de verdad ${ }^{30}$. En Gorgias define la música como un arte, una techné. No tiene la dignidad de una ciencia y su utilidad radica en el hecho de producir placer. De esta forma resultan contrastantes las opiniones que se vierten en los diálogos acerca del arte musical y la práctica de la música.

En Las Leyes se habla de la música como instrumento educativo de primer orden, junto con la gimnasia. Esta última educa el cuerpo, pero la música sirve para la «serenidad del alma». Esta teoría educativa entronca con el aspecto conservador de Platón que, como hemos visto juzgaba como música buena las de los nomoi tradicionales. Desdeñaba la música de su época de innovación melódica y por lo tanto, desviada de los patrones melódicos tradicionales y propugnaba una vuelta a los nomoi arcaicos. Para Platón la música no sólo es la que es objeto de nuestros sentidos. La música se vincula en Platón y en Pitágoras con la teoría de la reminiscencia, «facilita el ejercicio de esa memoria de todo cuanto existe que el recién nacido pierde al abrevarse en el río del Olvido (del que se habla en el mito de Er Libro X de la República de Platón). Como se explica en el Timeo, toda alma, cósmica o individual, está constituida según un número y proporción, atendiendo a las principales consonancias musicales». ${ }^{31}$ En su unión con el cuerpo, según la conocida teoría socrático-platónica de la anámnesis, de honda raigambre pitagórica ${ }^{32}$, nuestra alma pierde el recuerdo de las armonías del cosmos, que le son inherentes: «El reencuentro con estas es la tarea de la filosofía, acompañada de la música y las matemáticas. El objetivo que se persigue...es la salud del alma que ese cuidado proporciona. Y esa salud permite alcanzar la eudaimonía, el mejor de los destinos. La música proporciona esa forma de sintonía entre alma y cosmos que ese cuidado socrático facilita. Es música que orienta el ethos. Y que por tanto debe ser objeto preferente de consideración en toda reflexión cívica y política ${ }^{33}$. Como vemos, en estos juicios, la importancia de la consideración moral de la música llega a extremos elevadísimos en su consideración pedagógica y ética. «Platón creía que la música podía implantar todas las virtudes (valor, moderación e incluso justicia) en el carácter humano, es explicable que Platón abogara por el uso de la música como continuación de la política estatal. Sostenía que la música formaba el carácter no sólo del ciudadano, sino del Estado como totalidad; la música podía, en efecto, apoyar o subvertir el orden social establecido, pues, (como dice en la República), «cuando cambian los modos de la música, las leyes fundamentales del estado siempre cambian con ellos» ${ }^{34}$.

Pero veamos brevemente la función de la música en la educación platónica en cada uno de los dos grandes diálogos que contienen el proyecto político-pedagógico del filósofo ateniense, las Leyes y la República. En el proyecto político de Platón la consideración ética y educativa está siempre presente, pues solo individuos justos pueden componer la ciudad justa y solo la armonía interna puede dar lugar a una armonía global, siguiendo los postulados políticos que ya estaban presentes en el pitagorismo. El pitagorismo había

\footnotetext{
${ }^{30}$ Fubini, 1987, 56

${ }^{31}$ Cita de Trías, 2008, 811.

32 Cf. también Hernández de la Fuente, 2011, 138-155.

33 Trías, 2008, 810.

34 Rowell, 1990, 59.
} 
formulado la idea de armonía en el macrocosmos, regida, como las escalas musicales, por proporciones matemáticas, y también en el microcosmos, en el alma del hombre.

Platón retoma esta equivalencia entre ciudad ideal y alma justa. Solamente formando ciudadanos justos, y repartiendo sus funciones en virtud de su calidad ética y psicológica, podremos obtener el estado ideal. Esta educación integral, sin embargo, solo puede ser alcanzada por los estratos superiores, los guardianes de la ciudad de la República, los gobernantes filósofos, que culminarán todo el iter de la formación filosófica tras separarse de la educación común. Cabe preguntarse qué tipo de educación recibirán las otras dos clases, que se deja en una ambigüedad calculada. En la República el proceso educativo está dividido en dos etapas, una, en la infancia y juventud, y otra que va desde la mayoría de edad a la madurez. Mientras que la primera fase está destinada a la formación de los auxiliares o guerreros, la segunda apunta a la formación de quienes llegarán a ser gobernantes-guardianes y se corresponden, siguiendo esta dualidad, al desarrollo del cuerpo y al del alma, definiéndose como gimnasia y música ${ }^{35}$.

Se trata de un proyecto unitario para formar ciudadanos integrales pero respondiendo a sus clases diferenciadas y a los tipos de alma, desde la formación del ánimo y de las virtudes que se relacionan con él, hasta el modelado de la parte más intelectiva mediante la educación musical, que es una suerte de formación humanística, filosófica, matemática y artística fundamental para la educación de la clase gobernante. Mientras que los auxiliares han de ser educados para tener una opinión (doxa) firme y recta, el saber verdadero (episteme) se reservará para las clases dirigentes.

Sin duda, la diferencia entre los niveles de la educación estriba en el arte musical, en la techne mousiké. La música se configura como el instrumento educativo por excelencia ${ }^{36}$. La música y la poesía, indisolublemente unidas, son fundamentales para este proyecto político, y de ahí el gran interés que tienen las páginas que dedica Platón a su teoría poética y a la clase de arte que debe tener cabida en esta ciudad. La célebre censura de los poetas tradicionales, sobre todo a los poemas épicos tradicionales, de Homero y Hesíodo, y los autores de tragedia, género este último íntimamente relacionado con el sistema democrático ateniense, se explica porque la temática y los personajes deben ser adecuadas para la finalidad educativa. Se trata de una cuestión de mímesis, del modelo que se propone para la imitación en el sistema educativo platónico. El destierro de cierta poesía que postula modelos no convenientes para la comunidad queda claramente evidenciado. Pero no todos los géneros de la poesía son tan duramente criticados en la República. Sin embargo, no todo el arte poético es condenado: hay un tipo de poema de índole musical y arcaica que se salva de la censura de Platón por ser tradicional, inmutable y digno de imitación y enseñanza a las nuevas generaciones de ciudadanos. La tragedia y la comedia parecen objetable al filósofo, ya que son esencialmente artes miméticas, es decir, que imitan las acciones humanas ${ }^{37}$. Sin embargo, hay un balance más positivo para otros géneros como la épica, un género mixto entre la narración y el teatro, o la poesía lírica que, de acuerdo con este pasaje, es pura narración sin mimesis. Pero sorprendentemente, la referencia a la lírica se obra mediante el término técnico

\footnotetext{
35 Calvo 1995, 174-181.

36 Platón, República 376e; 386a ss., etc.

37 Platón, República 394c.
} 
«ditirambo», un género de la poesía lírica coral que, acompañado por música, se dedica a Dioniso, así como el Peán es el himno que pertenece por excelencia a Apolo. En este sentido, se han querido ver en la República restos de cierto arcaísmo religioso y, a la par, una devoción por un tipo de educación musical relacionada con la tradición pedagógica del mundo dorio, lo que no está lejos de la realidad. En efecto, Platón muestra a menudo fascinación por las tradiciones religiosas y culturales, en concreto las del pueblo dorio, y no esconde ciertas simpatías por Esparta ${ }^{38}$. Hay estudiosos que han leído así el comunismo de la República, el papel de la mujer o ciertas preferencias en la educación musical y poética por géneros corales.

Así, una vez superada esta primera fase educativa en sus dos vías, la física y la musical, los que han sido seleccionados por su naturaleza para seguir la senda del sabio pasan a la etapa siguiente. Se trata de quienes hayan destacado más entre los ciudadanos por su amor por la ciudad y por su excelencia en el estudio. La metafísica platónica y la teoría del conocimiento son pilares fundamentales de este currículo del sabio. La justicia y armonía interior solo se pueden obtener a través de una profunda formación filosófica en materias como la matemática, la geometría, la astronomía y, de ahí, la extrema importancia de esta educación superior en el proyecto político platónico, centrada en la doctrina del alma y del conocimiento, en la célebre teoría de las ideas que se enuncia en la parte central de la República, al final del libro V y en los libros VI y VII.

El método de alcanzar este conocimiento, mediante la dialéctica, está en consonancia con anteriores diálogos de Platón. Se trata de un ascenso gradual en el conocimiento, en el amor a la sabiduría, a la justicia y al bien, en pos de la contemplación más allá del mundo sensible hasta llegar a la Idea del Bien. Mediante estos entrenamientos intelectuales y despojados de todas las pasiones mundanas, los sabios podrán regir con justicia la ciudad y ser los guardianes perfectos de la comunidad política (Platón, República, 518b-d). Platón postula la contemplación del nivel ontológico más alto, tal vez la escucha de la música de las esferas, para sus gobernantes filósofos del más alto nivel.

Ahora procede pasar a las Leyes. Junto a la propia fundación de la ciudad, la importancia de la música en la ciudad platónica de las Leyes se deja sentir especialmente. Al comienzo de la obra, y tras examinar la legislación legendaria de Creta y Esparta, modelos dorios presumibles de Platón tanto en la República como en las Leyes, el extranjero ateniense analiza, a modo de preámbulo, ciertos motivos previos para algunas instituciones que han de inspirar la ciudad proyectada de Magnesia. En seguida se llega a la cuestión del simposio, cuando se exponen las facilidades para el ejercicio de la virtud, el coraje y la fortaleza en Esparta. Entonces se llega a la cuestión de si es admisible en una sociedad ideal el disfrute del simposio, entre música y vino. Aquí el extranjero ateniense contradice la tradición doria y sostiene la que ausencia absoluta de vino en Esparta es algo negativo ${ }^{39}$ y propone un uso controlado y educativo de los simposios, con el objetivo de educar a los ciudadanos a modular los placeres en el simposio y, por tanto, a ejercitarse en la virtud y el coraje.

La educación musical y en la poesía aparece con gran importancia en las Leyes, cuyo libro II se refiere a la importancia de la música para la educación del alma, en una

\footnotetext{
38 Isnardi Parente, 1981, 208-209.

39 Platón, Leyes 674d.
} 
discusión sobre los coros apolíneos y dionisíacos que se sitúa antes de que empiece la legislación de la ciudad propiamente dicha, como una especie de preámbulo. También las Leyes se oponen al libre desarrollo de la función poética, salvo si se someten a una estricta censura, pues el poder de la poesía es enorme y los legisladores han de proteger a la población regulándola según la ley y la justicia. Llama la atención, no obstante, que las palabras que se dirigen a los poetas son respetuosas y recuerdan al Ión y a la consideración de la locura divina de los poetas en el Fedro: se les llama «hombres divinos», «los mejores extranjeros» y el legislador les considera en cierto modo rivales:

«También nosotros somos poetas trágicos, y nuestra tragedia [...] es la mejor y más noble. Tanto vosotros como nosotros somos poetas... rivales y antagonistas en el más noble de los dramas, que solo la verdadera ley puede hacer perfecto ${ }^{40}$.»

La ciudad debe estar bajo el hechizo de la ley pues esta misma parece una poseer los caracteres de la poesía musical, de la téchne mousiké: se compara los preámbulos de la ley con preludios musicales y poéticos: «medidas de la lírica y la música y de todo tipo deben tener preludios elaborados con el mayor cuidado ${ }^{41} \mathrm{y}$ también las leyes deben ser precedidas por este tipo de preludios, del que el episodio del coro de Dioniso es un ejemplo; en la obra, el nomos, como melodía y ley, aparece con sentido ambivalente. La presencia del culto a dioses diversos del panteón tradicional, en una nueva lectura filosófico-política, es muy notable en las Leyes y sobre todo en el libro II, que funciona como una suerte de preludio, pues se ve positivamente la contribución del simposio para la educación del alma. Así, el extranjero ateniense propone establecer tres coros musicales bajo el patrocinio de diferentes dioses para educar a los ciudadanos de diversas edades:

«Decíamos que como los dioses se compadecieron de nosotros nos dieron como compañeros de baile y jefes de danzas a Apolo y las Musas y en tercer lugar, si recodamos bien, a Dioniso.

Cl. ¿Cómo no íbamos a recordarlo?

At. Así pues se ha hablado del coro de Apolo y del de las Musas, pero se debe hablar por fuerza también del tercer coro restante, el de Dioniso.

Cl. ¿Y cómo? Habla, pues sería harto insólito, al menos para el que escucha de repente, un coro de ancianos bajo el mando de Dioniso, si han de bailar los que tienen más de treinta y cincuenta años hasta incluso los de sesenta.

At. Dices toda la verdad, pero es necesario, según creo, argumentar cómo podría hacerse esto de forma razonable.

Cl. Ciertamente.

At. ¿Acaso no estamos de acuerdo en lo anterior?

Cl. ¿A qué te refieres?

At. A que conviene que todo hombre y niño, libre y esclavo, mujer y varón, y la ciudad entera no deje nunca de entonar encantos para sí mismos en todo momento sobre las cosas que hemos explicado, cambiándolas siempre de algún modo y dándoles cierta variedad en lo posible, de forma que se genere en los que cantan unas ganas insaciables de himnos y un placer en ellos.» ${ }^{42}$

\footnotetext{
40 Platón, Leyes 817 b.

41 Platón, Leyes 722e.

${ }^{42}$ Platón, Leyes 665 a-b. Trad. D. Hernández de la Fuente.
} 
El más importante es el coro de Dioniso, para el que se establecen diferentes reglas, en cuanto a cómo dirigir el simposio, a qué canciones cantar y a cómo cantarlas, que he de ser lo mejor del arte poético. El tema de la educación musical fue siempre la principal preocupación del filósofo y en el caso del control del coro de Dionisio, podemos confirmar un uso político del culto a Dioniso, un dios que es descrito a menudo erróneamente como dios apolítico. En comparación con la República, este pasaje no tiene por qué causar confusión o suponer una contradicción si se lee a la luz de la consideración platónica del simposio filosófico, de la poesía musical arcaica.

En comparación con la educación tal y como se proyecta en la República y con la célebre censura de los poetas, especialmente los escritores de tragedias, hay que mencionar que tampoco se menciona positivamente el teatro en las Leyes. Sin duda, su función educativa en la democracia ateniense no podía hacerlo aceptable para Platón. El enfoque de la educación de la ciudad utópica de Platón está más bien en el coro, en la lírica coral, arcaica, aristocrática, prestigiosa y prodoria (seguramente sea posible situar a Platón en la tradición de las facciones más o menos confesadamente prolacedemonias de la sociedad ateniense). No hay teatro, pero la propia ley de la ciudad es la poesía dramática y Dioniso está todavía allí, como en la República. Cuando se habla de los diferentes tipos de música y de la poesía mejor, la inmutable y tradicional en las Leyes, se menciona «el llamado ditirambo, una invención, creo yo, de Dioniso» (700b). La ley se traduce en una suerte de encantamiento musical gracias a los preámbulos y los coros dirigidos bajo la advocación de divinidades diversas y representa el nomos antiguo. Recordemos que, en griego, nomos, quiere decir, a la vez, ley y modo musical y que en Platón aparece con sentido ambiguo. En paralelo, la República encomiaba el ditirambo como ejemplo de poesía narrativa en la que el poeta, como un legislador, es el único que habla, bajo el influjo del dios de la inspiración poética ${ }^{43}$. Así, el nexo entre educación del alma y música aparece también en el libro VII, que contiene disposiciones para las danzas y cantos que formarán a la juventud, en relación directa con la discusión en los dos primeros libros de las Leyes acerca de la búsqueda de la virtud, al hablar del término medio entre placeres y dolores y cómo lograr la areté en los ciudadanos ${ }^{44}$. La educación del alma de los jóvenes es confiada por Platón a la práctica de las artes y la música, además de la gimnasia, lo que constituye, en el libro VII, la concreción de las teorías generales expuestas en los libros anteriores acerca de la virtud y la paideia. Y tal divinidad, según parece claro a partir de diversos indicios, no es otra que el par divino Apolo / Dioniso. Estos dos dioses son patrones del canto y el baile, y también representan el dominio de los placeres y dolores: no hay que perder de vista que a ambos se debe el patronazgo alternante de Delfos. A través de ellos, se lleva a término el proyecto legislativo de ciudad ideal mediante los coros, a los que se dedica atención en este mismo libro ${ }^{45}$. La paideia musical recibe entonces un tratamiento destacado y pronto se dedican ciertas disposiciones a regular el canto y la danza, como elementos sagrados de la educación del ciudadano ${ }^{46}$. Contravenirlas sería impiedad y blasfemia, y como tal han de ser castigados los que atenten

\footnotetext{
${ }^{43}$ Platón, República 394c.

44 Platón, Leyes $792 c$-d.

45 Platón, Leyes $796 e$.

${ }^{46}$ Desde Platón, Leyes 800 a.
} 
contra la correcta educación de la juventud. Se compara, poco después, con el ejemplo del joven que atenta contra los sacrificios a los dioses y las adivinaciones, lanzando blasfemias contra alguien: «¿no acarrearían sus palabras desánimo y malos presagios para su padre o sus otros familiares? $\gg{ }^{47}$ Ello causaría, así, un efecto parecido al del joven que no siguiera las reglas de la educación para coros y danzas: se ha de prevenir y castigar esto como origen de males para la comunidad.

Veamos ahora cómo discurre Aristóteles sobre la cuestión de la música y su valor social. El principal discurso de Aristóteles sobre la música se inserta en el Libro VIII de la Política, dedicado a la educación. Después de hacer el elenco de las materias a enseñar en la tradición didáctica vigente: escritura, gimnasia, música y, dibujo, advierte de las muchas discusiones acerca de la música «los antiguos hicieron de ella una parte necesaria de la educación, persuadidos de que la naturaleza misma, exige de nosotros no sólo un loable empleo de nuestra actividad sino también un empleo noble de nuestros momentos de ocio» ${ }^{48}$. La música es considerada una de las materias vertebradoras de la educación en Grecia, y Aristóteles señala por primera vez su importancia no sólo formativa sino como una de las actividades más dignas para el tiempo de ocio.

«Los objetivos de la música y la educación eran idénticos:

Paideia: educación en general, preparación moral en lo específico

Kátharsis: purgación

Diagogé: conocimiento intelectual

Paidiá y anapausis: juego y relajación ${ }^{49}$.»

Como vemos, no solamente Aristóteles trata los aspectos más formales de la música, sino que analiza todo el espectro de actividades y repercusiones morales, éticas y lúdicas.

Para Aristóteles la música es una ocupación para el tiempo libre, abre un abismo entre el acto de escuchar y el de producir la música. «La primera es una actividad no manual, digna de un hombre libre; la segunda es un oficio, un trabajo manual, y no se inserta dentro de la educación liberal ${ }^{50}$. Esta distinción de la actividad de escuchar la música, y de esta forma disfrutar de ella, y el acto de producirla en el cual Aristóteles se está refiriendo a una posible profesionalización del músico, se produce una fractura entre una posición de espectador, eso sí, activo y que disfruta de las bondades de la música, y una profesionalización, que al verse vinculada a un hacer manual, no tiene la alta consideración de otras actividades que Aristóteles considera de más dignidad. Así, lo que no resulta recomendable es ser profesional de la música, sino, simplemente, escuchar y disfrutar de los sonidos.

Las ideas políticas de Aristóteles aparecen también marcadas, como las de su maestro Platón, por el empeño en la educación del espíritu del ciudadano y, en concreto, por el gran énfasis en la música. En cambio Aristóteles, frente a Platón, se ciñe a lo posible y limita el recurso a soluciones utópicas o demasiado innovadoras a los problemas constitucionales que han sido heredados de la tradición y casi se diría que el Estagirita prefiere

\footnotetext{
47 Platón, Leyes $800 c$.

48 Aristóteles Política, VIII, $1337 \mathrm{~b}$.

49 Rowell, 1990, 58.

50 Fubini, 1987, 68.
} 
combinar los materiales ya existentes en esa misma tradición para elaborar un «equilibrio dorado». Así se desprende también de su regulación de la educación, que responde plenamente a parámetros conservadores tradicionales.

En los libros IV y V la regulación de la ciudad perfecta incluye el necesario cuidado del legislador por la educación desde la primera infancia, prohibiéndose el contacto con los esclavos y estipulando los niveles educativos. En un primer momento, desde los cinco a siete años, los niños asisten a las lecciones sin tomar parte en ellas. En la educación propiamente dicha, se distingue la infancia, de los siete años a los catorce, y la juventud, desde la pubertad a los veintiún años. El sistema educativo será público y se ocupará del cuerpo y del espíritu en igual medida: lectura y escritura, gimnástica y música son las partes principales y sirven para formar al ciudadano que disfrutará del ocio necesario para las labores superiores de la dirección de la ciudad y de la teorización filosófica.

Hay una clara apología del concepto de tiempo libre (scholé), el lapso de tiempo alejado de las tareas manuales y de cualquier otra ocupación inferior y alimenticia (prágmata), que se relaciona directamente con la educación y está ligado a las altas ocupaciones del ciudadano de pro: la gestión política y la especulación teórica ${ }^{51}$. Como dice en la Política, «en el primer principio de toda buena acción está el ocio». El ocio representa una forma de vida característica de una clase social ciudadana acomodada y se inserta en la discusión filosófica acerca del mejor género de vida, la vida contemplativa (bios theoretikós) frente a la vida práctica (bios praktikós) ${ }^{52}$. El distanciamiento entre el filósofo y el resto de los hombres surge de esta idea de vivir separado del mundo y del trabajo servil y cotidiano.

La scholé pasará así de designar el ocio a denotar aquello en lo que el ocio es empleado según el ideal filosófico, esto es, la charla entre amigos, la conversación entre discípulos y maestros y, por ende, en la discusión intelectual y la escuela ${ }^{53}$. La noción se extendió hasta designar el grupo de personas a los que un mismo maestro impartía lecciones, como aparece en la Política de Aristóteles ${ }^{54}$. En la Política la felicidad (eudaimonía) aparece como el fin último de la vida de los hombres, una forma de actividad (energeia) deseable, autosuficiente y conforme a virtud, sobre la base de una oposición frente a aquellas actividades que, según la opinión común, tienen fama de procurar la felicidad y cuyo común denominador está constituido por el juego (paidiá).

Además de una cierta referencia a los postulados de su maestro Platón, este tratamiento ético del tiempo libre deslinda definitivamente el ocio popular (descanso, placer, juego) de un ocio digno del desarrollo apropiado del individuo y de la sociedad relacionado con la especulación filosófica. Al ensalzar la necesidad de tiempo libre en un estado bien ordenado, Aristóteles continua la huella de su maestro Platón, pues pretende también que el estado se ocupe de la educación en las virtudes que hacen posible la mejor convivencia y la justicia en la polis: la ciudad ha de promover un ocio equilibrado.

Así, en el tratamiento que hace Aristóteles en los libros VII y VIII de la Política sobre el sistema político ideal y su relación con los individuos, el énfasis en la educación

\footnotetext{
51 Hernández de la Fuente 2012.

52 Joly, 1956.

53 Platón, Leyes 820c, Aristóteles, Política $1323 b 39$.

${ }^{54}$ Aristóteles, Política 1313 b3.
} 
musical aparece en armonía con la noción de ocio digno y de escuela. Como en el caso de Platón, el discípulo se centra de nuevo en dos temas clave para la ciudad ideal, la educación y la justicia, acaso de una manera más pragmática que en las obras políticas del maestro. El libro séptimo resume la vida virtuosa que debe acompañar a la virtud política para armonizar la virtud individual con las leyes de la ciudad.

La felicidad humana se pone en relación con el mencionado debate filosófico entre la vida activa y la vida contemplativa, en aras a conseguir el sistema político de la ciudad ideal. El estudio que se emprende de esta va a analizar diversos aspectos en detalle, desde su tamaño y territorio hasta el tipo de ciudadanos que le conviene tener, los templos o murallas y los edificios públicos. Especial hincapié se hace en las clases sociales en que debe estar dividida la ciudad y en los medios para alcanzar la felicidad general. Entre estos, por supuesto, destaca la formación del ciudadano siguiendo los principios generales de una educación virtuosa y estructurada en etapas, pero también la regulación del matrimonio y de la natalidad.

A la educación de los jóvenes se dedica en especial el libro octavo, que examina los tipos de sistemas educativos disponibles y se decanta por una paideia marcada por la tradición y estructurada en gramática, gimnasia y música. La insistencia en la educación en la música empareja la política aristotélica con los proyectos platónicos y recuerda de nuevo el doble significado de la palabra nomos, que alude tanto a la ley como a los modos musicales.

En los últimos capítulos del Libro VIII de La Política establece «el primer tratado orgánico que sobre música nos ha legado la Antigüedad» ${ }^{55}$. Tratará de establecer unos fines educativos inherentes a la música, indicar qué melodías y qué ritmos son educativos o no. Mantiene invariable su aversión al ejercicio profesional de la música para el hombre libre. Por ello, interpretar la música será sólo un paso para poder juzgar la calidad de la música. «Desde esta perspectiva, es evidente que la práctica musical debe detenerse cuando se alcanza el umbral del virtuosismo, cuando se llega a una excesiva fatiga, o incluso cuando se trata de instrumentos excesivamente difíciles como la flauta o la cítara, que requieren competencia específica» ${ }^{56}$.

Excluida la música como profesión, Aristóteles en la Política trata de analizar de forma exacta en qué consiste el valor educativo de la música. Contaba con dos tradiciones, una explicación se ajustaba al modelo pitagórico. Para esta corriente filosófica, la música estaría en relación orgánica con el alma, porque el alma, como la música es armonía y, por esto puede devolver la armonía cuando esta se ha visto turbada. El otro modelo es el de Damón de Atenas, uno de los maestros de Sócrates que fue de los principales defensores de la conexión específica de la música y la formación del carácter del hombre. «Según la teoría se puede hacer retroceder hasta Damón, la relación entre la música y el alma, se vería en función del concepto de imitación, verdaderamente, ciertas melodías, ciertos ritmos, ciertas armonías, imitan virtudes, aunque también los vicios, y debido a esto, la música tiene un poder educativo si se la usa con prudencia y con conocimiento de sus efectos sobre el espíritu humano» ${ }^{57}$.

\footnotetext{
55 Fubini, 1987, 69.

${ }^{56}$ Fubini, 1987, 69

${ }^{57}$ Fubini 1987, 70.
} 
Para Aristóteles, el arte es imitación y suscita sentimientos, por eso es educativo. El beneficio que se puede obtener es a través de la catarsis. «Aristóteles debió entender la catarsis como una medicina homeopática ${ }^{58}$. No hay armonías o músicas dañinas en absoluto, desde el punto de vista ético; la música es una medicina para el espíritu cuando imita con propiedad las pasiones o emociones que nos atormentan, de las que queremos liberarnos o purificarnos ${ }^{59} \gg$.

«La música no se practica para obtener un único tipo de beneficio que de ella puede derivarse, sino para cumplir múltiples usos, puesto que puede servir para la educación, para procurar la catarsis, y, en tercer lugar para el reposo, la elevación del espíritu y la interrupción de las fatigas ${ }^{60}$. De esta manera se abren más las posibilidades de la música que la del comportamiento moral, acepta el placer derivado de la música, explicitándolo muchas veces a lo largo de La Política. En los Problemas Musicales, Aristóteles insiste más en los valores formales de la música. Intenta clarificar de qué manera los sonidos pueden imitar los hábitos. El sonido es movimiento, y el movimiento es lo que conecta el sonido y el $e t_{h o s}{ }^{61}$. El movimiento en la música implica la idea de orden, de proporción, en el sentido pitagórico. Pero Aristóteles interpreta estas cualidades desde un punto de vista puramente psicológico. La afinidad entre el sonido, y el mundo de las emociones (miedo, piedad) y del ethos, por otra, es de naturaleza formal e indirecta: el movimiento es el elemento común a estos dos mundos. «Naturalmente, nuestro espíritu experimenta placer con el movimiento ordenado, dado que el orden es consustancial a la naturaleza, y la música encarna y reproduce del modo más variado, a través de sus ritmos y de sus armonías, el orden natural ${ }^{62}$.

En Aristóteles se supera la dicotomía entre la música como hecho empírico y la teoría metafísica de los pitagóricos y Platón y se abre otra fractura, entre la ejecución musical y el disfrute musical, excluyendo la música «como profesión y como práctica más allá de los límites de preparación para el acto de escuchar» ${ }^{63}$.

Las teorías sobre la música de San Agustín (354-430) y de Santo Tomás (1225-1274) llegarán a un acuerdo con los principios teóricos de Platón y Aristóteles. Compartieron la ambivalencia tradicional de la Iglesia Romana con el arte, «desconfiaban de él por sus placeres sensuales creadores de adicción, su énfasis en la belleza y sus persistentes asociaciones con la cultura pagana; pero a la vez les atraía su excelencia intrínseca y su capacidad de representar la belleza eterna ${ }^{64} \gg$. Sin embargo, el binomio música y sociedad seguirá avanzando mano a mano en el pensamiento social, en los proyectos utópicos y, siglos después, en el nacimiento de la sociología.

Por supuesto, Grecia es solo el principio. Desde entonces, y como hemos argumentado en otro lugar, la noción de que la música es fundamental para el mejoramiento del individuo y, lo que es más importante, como modelo no solo espiritual sino también organizativo para una sociedad ideal, será una herencia constante en la historia del pensamiento de occidente.

\footnotetext{
58 Fubini, 1987, 70.

59 Fubini, 1987, 71.

${ }^{60}$ Aristóteles, Política $1342 \mathrm{~b}$.

${ }^{61}$ Ethos abarca un enorme campo semántico: costumbre, hábito, manera de ser, pensar o sentir, conducta, carácter, temperamento, moral y moralidad.

${ }^{62}$ Fubini, 1987, 72. Aristóteles, Problemas Musicales, 38

63 Fubini, 1987, 69.

64 Rowell, 1990, 92.
} 


\section{BIBLIOGRAFÍA}

Bergua J. (2012). La música de los clásicos, Valencia, Pretextos.

BütTner, S. (2006). Antike Ästhetik: Eine Einführung in die Prinzipien des Schönen, C. H. Beck, Múnich.

Calvo T. (1995). De los sofistas a Platón: política y pensamiento, Madrid, Cincel.

Fubini E. (1988). La estética musical desde la Antigüedad hasta el siglo XX, Madrid, Alianza.

Hernández de la Fuente D. (2011). Vidas de Pitágoras, Vilaür, Atalanta.

- (2012). «La escuela del ocio: Tiempo libre y filosofía antigua», Cuadernos hispanoamericanos, 747, (2012) 77-100.

Isnardi Parente M, (1981). En «Sócrates y Platón: del intelectualismo al trascendentalismo» en Bianchi Bandinelli R, (1981) Historia y civilización de los griegos, vol. V: La crisis de la polis: historia, literatura, filosofía. Barcelona, Icaria.

Joly R. (1956). Le thème philosophique des genres de vie, Paris.

Kahn C. (2001). Pythagoras and the Pythagoreans: A Brief History, Hackett Publishing Company. Konstan, D. (1997). Friendship in the Classical World. Cambridge: Cambridge University Press. Martínez Hernández, M. (2010). «Música y palabra en la mitología griega», en G. Santana y E. Padorno (eds.), La palabra y la música, Ediciones Clásicas, Madrid,11-68.

Riedweg, C. Pythagoras: Leben, Lehre, Nachwirkung. Eine Einführung, München: C. H. Beck 2002 [trad. ing. Cornell University Press, 2005].

Rowell L. (1990). Introducción a la filosofía de la Música, Madrid, Gedisa.

Tatarkiewicz W. (1987). Historia de la estética, Madrid, Akal.

Trías E. (2008) El Canto de las Sirenas, Barcelona, Galaxia Gutenberg. 
